\title{
Sağlık Eğitimi Almamış Hastane Personelinin Tıbbi Malzemelerle İlgili Bilgi Düzeyleri
}

\author{
Alihan 0ral
}

İstanbul Bilim Üniversitesi, İç Hastalıkları Anabilim Dalı, İstanbul, Türkiye

Alihan Oral, Dr. Öğr. Üyesi

İletişim:

Dr. Öğr. Üyesi Alihan Oral

İstanbul Bilim Üniversitesi, Iç Hastalıkları

Anabilim Dalı, İstanbul, Türkiye

Tel: +905546142121

E-Posta:dralihanoral@gmail.com
ÖZET

Giriş ve Amaç: Hastanelerde personellerin uyum içinde çalışması hem hasta için hem de sağılık çalışanları için büyük önem taşımaktadır. Bu çalışma, sağlık eğitimi almayan personelin demografik özellikleri, eğitim düzeyleri, çalışma süreleri, iş eğitimi alıp almadıkları ve tıbbi malzemelerle ilgili bilgi düzeylerinin tespiti amaçlandı. Bu çalışma bu konuyla ilgili yapılmış ilk araştırma olacaktır.

Yöntem ve Gereçler: Mardin Kızıltepe Devlet Hastanesinde 1-15 Aralık 2018 tarihinde sağlık eğitimi almayan hastane personelinin tıbbi malzemelerle ilgili bilgi düzeylerini tespit etmeye yönelik anketle tarama modeli kullanılmıştı. Ankette ilk 6 soru tanıtııı özelliklerle, diğer 24 soru tıbbi malzeme bilgi düzeyi ilgiliydi. Tıbbi malzemeler, hastanelerde sık kullanılan tıbbi 24 malzemeden seçilmiştir (aspiratör, anjektör, ambu, larengoskop vb.). Bu verilerin analizinde SPSS 21 programı kullanılmıştır. Değerlendirmede frekans, dağılım, t-test ve korelasyon analizi kullanıldı.

Bulgular: Çalışmaya toplam 102 (\%84.3 erkek, \%15.7 kadın) personel katıldı. Yaş ortalaması 36.8 56.4 , bilgi düzeyi puan ortalaması: $16.3 \pm 4.6$ bulundu. Personellerin tıbbi malzemelerle ilgili bilgi düzeylerine bakıldığında aspiratör, batikon, sapanç gibi bazı malzemelerin herkes tarafından bilindiği; lam, pump cihazı, lökosit filtresi gibi bazılarının ise daha az kişi tarafından bilinmekteydi. Personellerin yaşı, cinsiyeti ve eğitim düzeyi ile tıbbi malzeme bilgi düzeyi arasındaki ilişkiye bakıldığında herhangi bir korelasyon izlenmedi. Çalışma süresi ile tıbbi malzemeyi bilgi düzeyi arasındaki ilişkiye bakıılığında ise anlamlı pozitif bir korelasyon izlendi.

Tartışma ve Sonuç: Personele verilecek meslek eğitiminin içeriği, çalışmanın sonucuna göre personelin bilgi düzeyinin daha düşük olduğu tıbbi malzemelerle ilgili olarak oluşturulmasında fayda vardır. Sağılı çalışanları arasında sağlanacak olan uyum sayesinde sağık hizmeti sunumu daha hızlı ve daha kaliteli hale gelebilecektir.

Anahtar sözcükler: Sağlık eğitimi, hastane personeli, tıbbi malzeme, bilgi düzeyi.

\section{THE LEVEL OF KNOWLEDGE ABOUT MEDICAL EQUIPMENT OF HOSPITAL PERSONNEL WITHOUT HEALTH EDUCATION}

\section{ABSTRACT}

Introduction: The harmony of the personnel in hospitals is important both for the patients and for the health workers. This study was aimed to determine the demographic characteristics, education levels, working hours, job training and the level of knowledge about medical equipment (TLOKAME) of the personnel without health education. This study will be the first study on this subject.

Methods: A questionnaire survey model was used to determine TLOKAME of the hospital personnel without health education on 1-15 December 2018 in Mardin Kızltepe State Hospital. The first 6 questions in the questionnaire were related to identifying features, the other 24 questions were related to TLOKAME. SPSS, Frequency, distribution, t-test and correlation analysis were used in the evaluation.

Results: A total of 102 ( $84.3 \%$ male, $15.7 \%$ female) personnel participated in the study. The mean age was $36.8 \pm 6.4$, and the mean knowledge level was $16.3 \pm 4$.6. Some materials such as aspirator, batticon, etc., were known by everyone, whereas pump devices and leukocyte filters, etc., were less known. There was no correlation between the age, gender and education level of the personnel and TLOKAME. ; however, there was a positive correlation between the length of employment and TLOKAME.

Discussion and Conclusion: Establishing the content of vocational training to be given to the personnel according to the results of the study, focusing on the less-known medical equipment will be more productive. The efficiency and quality of health care will increase due to the harmony between health workers.

Keywords: Health education, personnel, medical equipment, knowledge
Gönderilme Tarihi : 180 cak 2019

Revizyon Tarihi : 180cak 2019

Kabul Tarihi : 05 Mayıs 2019 
ağlık hizmetlerinin tüm dünyada olduğu gibi ülkemizde de genel olarak sunulduğu yerler hastanelerdir (1). Hastanelerde etkili ve verimli bir sağlık hizmeti sunumu, ekip çalışmasına, etkili bilgi paylaşımına ve işbirliğine bağlıdır (2). Hastanelerde görev yapan sağlık personelleri sağlık hizmetlerinin teknik ve teknolojisine göre işe alınmaktadır (1). Doktor ve hemşireler dışındaki personellerin de bu teknik bilgiye sahip olmaları sağlık sunumunu daha kolay hale getirebilmektedir.

Illaç, tıbbi cihaz ve malzemeler sağlık hizmet sunumunun en önemli bileşenlerindendir. Hastalıkların önlenmesi, tanı ve tedavisinde veya sağlıkla ilgili vücut yapı ve işlevlerini belirlemek, ölçmek, düzeltmek veya değiştirmek maksadıyla kullanılan nesne, araç, parça veya makineler tıbbi malzeme adını almaktadır (3). Hastanelerde hastaya müdahale edildiğinde yardımcı personelin kullanılacak tıbbi malzemeleri tanıması ve zamanında getirmesi müdahalenin zamanında yapılmasında önemli rol oynamakta ve zaman kaybını ile iş kaybını önleyebilmektedir. Doktor ve hemşire uyumu dışında diğer sağlık personeli (hastabakıcı, yardımcı sağlık elemanları, temizlik elemanı...) ile de uyumun sağlanması alınan sağlık hizmetini daha kaliteli hale getirebilmektedir. Sağlık eğitimi almayan hastane personelinin tıbbi malzemelerle ilgili bilgi düzeyleri, hastaya yapılacak müdahaleyi ve uyum içinde çalışma ortamını etkileyecektir. Bu nedenle, bu çalışmada, sağlık eğitimi almayan hastane personelinin sağlık hizmetlerinde kullanılan çeşitli tıbbi malzemelerle ilgili bilgi düzeylerinin ölçülmesi ve değerlendirilmesi amaçlandı. Literatür tarandığında bu konuyla ilgili yapılan herhangi bir çalışma bulunamadı, bu çalışma bu konuyla ilgili yapılmış ilk araştırma olacaktır.

\section{Gereç ve Yöntemler}

\section{Araştırmanın amacı}

Bu çalışmada amaç, Mardin Kızıltepe Devlet Hastanesi (MKDH)'nde çalışan ve sağlık eğitimi almayan hastane personelinin tıbbi malzemelerle ilgili bilgi düzeylerini tespit etmek ve değerlendirme sonuçlarını ortaya koymaktır.

\section{Araştırmanın önemi}

Bu çalışmada MKDH'nde çalışan ve sağlık eğitimi almayan hastane personelinin demografik özellikleri, eğitim düzeyleri, çalışma süreleri, iş eğitimi alıp almadıkları ve tıbbi malzemelerle ilgili bilgi düzeyleri tespit edilmeye çalışılmıştır.

\section{Araştırmanın hipotezleri}

- Sağlık eğitimi almayan hastane çalışanlarının tıbbi malzemelerle ilgili eğitim yani iş eğitimi almamıştır ve çalışanlar iş eğitimi almak isteyeceklerdir. (Hipotez 1)
- Sağlık eğitimi almayan hastane çalışanlarının yaş ortalaması yüksek, eğitim seviyeleri düşüktür. (Hipotez 2)

- Sağlık eğitimi almayan hastane çalışanlarının çoğunluğunu erkekler oluşturmaktadır. (Hipotez 3)

- Sağlık eğitimi almayan hastane çalışanlarının tıbbi malzemelerle ilgili bilgi düzeyleri ile yaş, eğitim düzeyi, çaIışma süresi arasında ilişki vardır. (Hipotez 4)

- Sağlık eğitimi almayan hastane çalışanlarının tıbbi malzemelerle ilgili bilgi düzeyinin ortaya konması verilecek eğitimin içeriği konusunda yol gösterici olacaktır. (Hipotez 5)

\section{Araştırmanın sınırlılıkları}

- Araştırma bulguları, anketin yapıldığı kurum çalışanlarının, anketin yapıldığı tarihteki tıbbi malzemelerle ilgili bilgi düzeylerini yansıtmaktadır.

- Anketle toplanan verilerin güvenilirliği ve geçerliliği, veri toplamada kullanılan tekniğin özellikleri ile sınırlıdır.

\section{Araştırmanın yöntemi}

MKDH'nde 1 Aralık-15 Aralık 2018 tarihinde çalışan ve sağlık eğitimi almayan hastane personelinin tıbbi malzemelerle ilgili bilgi düzeylerini tespit etmeye yönelik yapılan bu çalışmada tarama modeli esas alınmış̦tı. Çalışma için gerekli bilgilerin elde edilmesinde anket yöntemi kullanılmıştır. Çalışmada personellerin demografik özellikleri, eğitim düzeyleri, çalışma süreleri, iş eğitimi alıp almadıkları ve tıbbi malzemelerle ilgili bilgi düzeyleri tespit edilmeye çalışılmıştır. Tıbbi malzemeler hastanelerde sık kullanılan tıbbi malzemelerden seçilmiştir (aspiratör, batikon, larengoskop gibi). Bu verilerin analizinde SPSS 21 paket programı kullanılmıştır. Değerlendirmede frekans, dağılım, t-test ve korelasyon analizi kullanıldı. $\mathrm{P}<0.05$ değeri istatistiksel olarak anlamlı kabul edildi.

\section{Çalışma evreni ve örneklem}

Çalışmada MKDH'nde çalışan ve sağlık eğitimi almayan hastane personeli seçilmiştir. Personelin toplam 102 tanesi örneklem olarak seçilmiştir.

\section{Veri toplama aracının uygulanması}

Anket formunda, önce onay imzası sonrasında toplamda 30 soru sorulmuştur. İlk sorular olarak "yaşınız, cinsiyetiniz, eğitim durumunuz, çalışma süreniz" soruları açık uçlu olarak sorulmuştur." iş eğitimi aldınız mı, iş eğitimi almak ister misiniz "soruları kapalı uçlu olarak evet ve hayır seçenekleri sunulmuştur. Geriye kalan 24 tane soru ise tıbbi malzemelerle ilgili kapalı uçlu olarak sorulup evet ve hayır seçeneklerinden oluşmaktadır. Bilgi düzeyleri için her bir 
evet için 1 puan verilerek toplam 24 puan üzerinden değerlendirildi. 12 puan altında alan zayıf, 12-18 arası orta, 18 ve üstü alan iyi olarak tanımlandı.

\section{Etik durumlar}

Mardin Artuklu Üniversitesi Etik Kurulu'ndan (Onay Tarihi: 27.11.208 ve Karar No: 2018/01-7 ) çalışmanın yapılması için gerekli izinler alınmıştır. Katılımcılardan anket doldurulurken yazılı onam alınmıştır.

\section{Bulgular}

Çalışmaya katılan personellerin yaş ortalaması $36.8 \pm 6.4$ 'tü (dağııım, 24-52). Personellerin \%12.8'i 18-30 yaş aralığında, \%51'i 31-40 yaş aralığında, \%33.3'ü 41-50 yaş aralığında ve \%2.9'u 51 yaş ve üzeri yaş aralığındaydı. Personellerin \%84.3'ü erkek, \%15.7'si kadın, \%42'si ilkokul, \%52'si lise, $\% 1$ 'i ön lisans, \%4.9'u lisans mezunuydu, yüksek lisans mezunu yoktu. Personellerin \%4.8'i 1 yıl, \%10.9'u 2-4 yıl arası, \%21.6'sı 5- 6 yıl arası ve \%47.1'i 7-9 yıl arası ve \%15.7'si 10 yıl ve üzeri çalışma süresine sahipti. Personellerin \%100'ü iş eğitimini almış olduğunu \%71.6'sı işiyle ilgili meslek eğitiminin verilmesi gerektiğini, \%28.4'ü gerekmediğini belirtti (Tablo 1).

Çalışmaya katılan personellere anketteki sorularda belirtilen tıbbi malzemelerin ne olduğunu biliyorlarsa evet, bilmiyorlarsa hayır seçeneğini işaretlemeleri istendi çıkan sonuç şu şekildeydi:

Çalışmaya katılan personelin tıbbi malzemeleri ilgili bilgi düzeyi puan ortalaması: $16.3 \pm 4.61$ 'di (dağılım, 7- 24).

Çalışmaya katılan personellerin tamamı (\%100, n:102) aspiratörün, steril eldivenin, spançın, flasterin, batikon ve enjektörün, \%94.1'i kan tetkik tüplerinin, \%89.2'si bistürinin, $\% 77.5^{\prime} \mathrm{i}$ folay sondanın, $\% 76.5^{\prime} \mathrm{u}$ ambunun, $\% 70.6^{\prime} \mathrm{s}$ katajelin, \%67.6'sı nasogastrik sondanın, \%63.7'si defibrilatörün, \%62.7'si lavmanın, \%59.8'i stribin, \%56.9'u entübasyon tüpünün, \%51.0'i nazal kanülün, \%49.0'u intraketin, \%45.1'i larengoskopun, \%39.2'si doziflowun, \%38.2'si airwayin, \%34.3'ü lamın, \%28.4'ü pump cihazının, \%16.7'si lökosit filtresinin ne olduklarını bildikleri saptandı (Tablo 2).

Personellerin yaşı, cinsiyeti ve eğitim düzeyi ile tıbbi malzeme bilgi düzeyi arasındaki ilişkiye bakıldığında herhangi bir korelasyon izlenmedi (p: 0.87, p: 0.73, p: 0.30), çalışma süresi ile tıbbi malzemeyi bilgi düzeyi arasındaki ilișkiye bakıldığında ise istatiksel olarak anlamlı pozitif yönde bir korelasyon ilişkisi izlendi (R: 0.26, p: 0.04).
Tablo 1. Sağlik eğitimi almayan hastane personellerinin özellikleri

\begin{tabular}{lcc} 
Özellikler & Sayı $(\boldsymbol{n}=\mathbf{1 0 2})$ & $\%$ \\
\hline Yaş & 13 & \\
$18-30$ & 52 & 12.8 \\
$31-40$ & 34 & 51.0 \\
$41-50$ & 3 & 33.3 \\
$>50$ & & 2.9 \\
Cinsiyet & 86 & \\
Erkek & 16 & 84.3 \\
Kadın & & 15.7 \\
\hline Eğitim Durumu & 43 & \\
Ilkokul & 53 & 42.2 \\
Lise & 1 & 52.0 \\
Ön lisans & 5 & 1.0 \\
Lisans & 0 & 4.9 \\
Yüksek lisans & & 0.0 \\
\hline Çalışma Süresi(yıl) & 5 & \\
1 & 11 & 4.8 \\
$2-4$ & 22 & 10.9 \\
$5-6$ & 48 & 21.6 \\
$7-9$ & 16 & 47.1 \\
$>10$ & & 15.7 \\
\hline İş Eğitimi Alınması & 102 & \\
Evet & 0 & 100 \\
Hayır & & \\
\hline İs Eğitimi Alma isteği & 73 & 28.4 \\
Evet & 29 & \\
Hayır & & \\
& &
\end{tabular}

Tablo 2. Personellerin tibbı malzemelerle bilgi düzeyleri

\begin{tabular}{lcc} 
Tıbbi malzemeler & Evet(n)/Hayır(n) & Evet(\%)/Hayır(\%) \\
\hline Aspiratör & $102 / 0$ & $100 / 0$ \\
Steril eldiven & $120 / 0$ & $100 / 0$ \\
Spanç & $102 / 0$ & $100 / 0$ \\
Flaster & $102 / 0$ & $100 / 0$ \\
Batikon & $102 / 0$ & $100 / 0$ \\
Enjektör & $102 / 0$ & $100 / 0$ \\
Kan tetkik tüpleri & $96 / 6$ & $94.1 / 5.9$ \\
Bistüri & $91 / 11$ & $89.2 / 10.8$ \\
Foley sonda & $79 / 23$ & $77.5 / 22.5$ \\
Ambu & $78 / 24$ & $76.5 / 23.5$ \\
Katajel & $72 / 30$ & $70.6 / 29.4$ \\
Nazogastrik sonda & $69 / 33$ & $67.6 / 32.4$ \\
Defibrilatör & $65 / 37$ & $63.7 / 36.3$ \\
Lavman & $64 / 38$ & $62.7 / 37.3$ \\
Strip & $61 / 41$ & $59.8 / 40.2$ \\
Entübasyon tüpü & $58 / 44$ & $56.9 / 43.1$ \\
Nazal kanül & $52 / 50$ & $51.0 / 49.0$ \\
inraket & $50 / 52$ & $49.0 / 51.0$ \\
Larengokop & $46 / 56$ & $45.1 / 54.9$ \\
Doziflow & $40 / 62$ & $39.2 / 60.8$ \\
Airway & $39 / 63$ & $38.2 / 61.8$ \\
Lam & $35 / 67$ & $34.3 / 65.7$ \\
Pump cihazı & $29 / 73$ & $28.4 / 71.6$ \\
Lökosit filtresi & $17 / 85$ & $16.7 / 83.3$ \\
& &
\end{tabular}

\section{Tartışma ve Sonuç}

Literatüre bakıldığında bu konuyla ilgili yapılan çalışma olmadığından bu çalışma, benzer olabilecek çalışmalarla 
değerlendirilmiştir. Bu çalışmada sağlık eğitimi almayan hastane personelinin tamamı meslek eğitimi almış olduğunu belirtmiş (\%100) ve büyük çoğunluğu (\%71.6) meslek eğitimi verilmesi halinde yine almak istemektedir. Terzi ve arkadaşlarının (4), Akbolat ve arkadaşlarının (5), ve Hasçuhadar ve arkadaşlarının (6) yaptıkları çalışmalarda personellerin tıbbı atık ile ilgili eğitim alanların oranı sırasıyla \%80.5, \%66.9 ve \%61 bulunmuş. Bu açıdan bakıldığında bu çalışmada iş eğitimi alma oranları oldukça yüksek görülmektedir ama diğer çalışmaların sadece tıbbi atıkla ilgili eğitimi baz almaları da bu çalışmaya göre daha düşük çıkmasında rol oynamış olabilir.

Personelin çoğunluğu erkek (\%84.3), eğitim düzeyi düşük (\%94.2'i lise ve ilkokul) ve yaş olarak orta yaş grubuydu (\%87.2: 31yaş ve üzeri). Akbolat ve arkadaşlarının yapığı çalışmada ise sırasıyla \%73, \%60, \%22,3'tü (5). Bunda bu çalışmada sadece sağlık eğitimi almayan personelin alınması ve diğer çalışmada tüm sağlık personelinin alınması rol oynamış olabilir. Ayrıca bu çalışmada erkek cinsiyetinin daha fazla olması hem hastanelerin zor çalışma şartlarına, hem de kadınların zor çalışma ortamında çalışmak istememelerine bağlı olabilir.

Personelin bazı malzemelerle ilgili bilgi düzeylerinin çok iyi olduğu bazılarıyla ilgili bilgi düzeylerinin ise düşük olduğu görülmektedir (\%100, \%16.7). Taşçıoğlu'nun yaptığı çalışmada da tıbbi atıklarla ilgili farklı bilgi düzeyleri ortaya

\section{Kaynaklar}

1. Bektaş F, Hastanelerde çalışan sağlık personelinin moral ve motivasyonunu etkileyen faktörlerin hastane yönetimine katkısı Beyken Üniversitesi Sosyal Bilinler Enstitüsü İşletme Yönetimi Anabilim Dalı Hastane Ve Sğlık Kurumları Yönetimi Bilim Dalı Yüksek Lisans Programı, İstanbul 2014.

2. Hevner AR, March ST, Park J, Ram S. Design science in information systems research. MIS Quarterly: Management Information Systems. 2004:28:75-105.

3. WHO Medical Device Technical Series. Introduction to Medical Equipment Inventory Management. WHO 2011.

4. Terzi Ö, Aker S, Terzi Ö, Sünter AT, Pekșen Y. Hastane Temizlik Elemanları ve Mesleki Enfeksiyon Riski: Bilgi ve Davranışlar Üzerine Bir Çalışma. İnönü Üniversitesi Tıp Fakültesi Dergisi. 2009;1:7-12. http://dergipark.gov.tr/nwsals/issue/19983/213449 konmuştur (7). Bu durum personelin bazı malzemeleri sık kullandığına, çalıștığı servisin farklı olmasına bağlanabilir.

Personelin cinsiyeti, eğitim düzeyi ve yaşı ile malzeme bilgisi arasındaki ilişkiye bakıldığında anlamlı bir ilişki yoktu. Akbolat ve arkadaşlarının yaptığı çalışmada personelin eğitim düzeyi ile tıbbi atıklarla ilgili bilgi düzeyinde anlamlı bir ilişki bulunmuş (5). Böyle bir sonucun çıkmasında çalışmamızda personellerin çoğunluğunun eğitim düzeyinin düşük olmasının ve orta yaş grubu olmasının payı olabilir. Örneklemin küçüklüğü de yine rol oynamış olabilir.

Personelin çalışma süreleri ile malzeme bilgisi arasındaki ilişkiye bakıldığında ise pozitif bir korelasyon görüldü (p: 0.04). Hasçuhadar ve arkadaşlarının yaptığı çalışmada personelin çalışma süreleri ile tıbbi atıklarla ilgili bilgi düzeyi arasında herhangi bir ilişki bulunmamış (6). Bu çalışmada çalışma süresi ile tıbbi malzeme bilgi düzeyi arasındaki pozitif korelasyon tecrübeye bağlanabilir.

Sonuç olarak sağlık çalışanları arasında sağlanacak olan uyum sayesinde sağlık hizmeti sunumu daha hızlı ve daha kaliteli hale gelebilecektir. Personele verilecek meslek eğitiminin içeriği, çalışmanın sonucuna göre personelin bilgi düzeyinin daha düşük olduğu tıbbi malzemelerle ilgili olarak oluşturulmasında fayda vardır. Bu konuyla ilgili daha geniş çaplı araştırmaların yapılaması sağlık eğitimi almayan personelin tıbbi malzemelerle ilgili bilgi düzeyinin ortaya konmasında aydınlatıcı olacaktır.

5. Akbolat M, Işık O, Dede C, Çimen M. Sağlık Çalışanlarının Tıbbi Atık BilgiDüzeylerinin Değerlendirilmesi ACU Sağlık Bil Derg 2011:13140. http://hdl.handle.net/11443/187

6. Hasçuhadar M, Kaya Z, Şerbetçioğlu S, Arslan T, Altınkaya S. Ankara Atatürk Eğitim ve Arastırma Hastanesi Personelinin Tıbbi Atık Konusunda Bilgi Düzeyi. Turkish Medical Journal 2007;1:138-44

7. Taşçıoğlu İ, Lüleburgaz Devlet Hastanesi ve Lüleburgaz 82. Yıl Devlet Hastanelerinde Işs ve Çalışma Ortamından Kaynaklanan Riskler Ve Bu Riskleri Hemşirelerin Algılama Düzeylerinin Saptanması. Trakya Üniversitesi Sağlık Bilimleri Enstitüsü Halk Sağlığı Anabilim Dalı Yüksek Lisans Programı. Edirne: 2007. 